\title{
Has COVID-19 had an impact on prices? The case of the cruise industry
}

\author{
Josep Maria Espinet Rius ${ }^{1,2} \cdot$ Ariadna Gassiot-Melian $^{3}$
}

Received: 28 June 2021 / Accepted: 4 November 2021 / Published online: 22 November 2021

(c) The Author(s), under exclusive licence to Springer Nature Limited 2021

\begin{abstract}
One of the previously unknown and unexpected impact of COVID-19 is its effect on prices. The aim of this research is to estimate how prices in the cruise industry have changed since COVID-19 was declared a pandemic. To carry out this research the authors created an extensive database of prices from February 2019 to March 2021, which were collected from a leading Spanish online travel agency (OTA). Methodologically, this research uses descriptive and hedonic analyses. The main conclusion is that cruise prices have reduced, on average, by $4.3 \%$, although there are relevant differences between cruise companies, zone of departure, size, antiquity and rating of the ships, and the number of days between the date of capture and the date of cruise departure. Finally, several managerial implications are suggested from the results of this study.
\end{abstract}

Keywords COVID- $19 \cdot$ Crisis $\cdot$ Cruise $\cdot$ Hedonic approach $\cdot$ OTA $\cdot$ Prices

\section{Introduction}

It is now well-known that the tourism industry has been widely affected by the impact of Covid-19 mainly due to travel constraints, so exogenous and uncontrolled factors (Pan et al. 2021). One of the tourist activities that has been most affected by this pandemic is the cruise industry. Cruise ships were the hardest hit tourist activities from the beginning of this pandemic and images of people stuck in some vessels rapidly spread a rapid negative perception about them (e.g. cases in Diamond Princess February 2020, etc.). In other words, no other tourism sub-sector has appeared in the global news as often as cruises (Gössling et al. 2020). This material from the media may change people's perceptions and behaviours. For example, after seeing cruise passengers evacuated by their respective national governments,

Josep Maria Espinet Rius

josepmaria.espinet@mediterrani.com;

jmaespinet@gmail.com

Ariadna Gassiot-Melian

ariadna.gassiot@mediterrani.com

1 Departament d'Empresa, Universitat de Girona, Girona, Spain

2 Facultat de Ciències Econòmiques i Empresarials, Campus Montilivi, 17003 Girona, Spain

3 Facultat de Turisme, Pl. Ferrater i Mora, 1. Campus Barri Vell, 17004 Girona, Spain people may want to avoid risks and keep away from crowded and exotic destinations (Ioannides and Gyimóthy 2020). The cruise industry was among the first to be proactive and voluntarily suspend cruise operations, which occurred within $48 \mathrm{~h}$ of the declaration of the worldwide pandemic (CLIA 2020). Activity was stopped for a long time and only recently have companies begun to resume. In fact, every cruise companies ceased their activities in March 2020, approximately at the time when COVID-19 was declared a pandemic and started to spread around the world, and very few companies have resumed their activity at the time of writing, by midMay 2021. For example, some cruise companies that are currently operating are Aida, Coral, Dream Cruises, Hapag Lloyd, MSC, Royal Caribbean and TUI. The majority of the other cruise companies expect to resume their activity between May and August 2021 (Medcruise 2021). By looking back at these previous months, we can see that there has not been an agreed strategy between flag states and the states have been interested in protecting their territory, so that the cruise industry faces a major challenge due to the fact that itineraries go through different countries (Choquet and Sam-Lefebvre 2021).

It is obvious that, due to all these circumstances, the cruise industry situation is far from being in the position it was in before COVID-19 and the efforts made and the strategies followed by different destinations and cruise companies are so diverse it makes it difficult to get an integrated view of what is happening to the cruise industry and what 
comes next. Thus, to contribute to a better description of what is happening in the cruise industry, the aim of this study is to estimate how prices changed in the cruise industry since COVID-19 was declared a pandemic. This empirical research is supported by an extensive database created by the authors from a leading Spanish Online Travel Agency (OTA) and can be considered a first step to addressing the variation of prices in the cruise industry since COVID-19 was declared a pandemic. In fact, up to now, the studies published about the impact of COVID-19 have focused on the future and referred to expected strategies but very few have empirical evidence from the supply side to support that. The nearest results are those obtained by Lai and Wong (2021) who carried out a survey in the Macau hotel market and concluded that a reduction in prices is one of the strategies applied after a crisis. Our study tries to address this gap from the point of view of prices in the seriously hit cruise sector.

\section{Literature review}

Although it is not the aim of this study to widely analyse the impacts of a crisis, some insights are given as a general overview of the situation. COVID-19 can be considered more of a disaster than a crisis ("a disaster can be defined as where an enterprise... is confronted with sudden unpredictable catastrophic changes over which it has little control"-Faulkner 2001, p.136) although usually both are used and analysed interchangeably. Wut et al. (2021) summarize the main research into crisis management in the hospitality and tourism industry and suggest focusing on less explored industry sectors, such as the cruise industry. Specifically, when a crisis comes from a health disaster, as with COVID19 , there is a gradual deterioration in health status, which in turn influences labor productivity and finally leads to fewer outputs in the tourism industry from the supply side, and makes tourism demand decrease due to government restrictions and mobility limitations (Yang et al. 2020). Although the impact of crisis and disasters cannot be stopped, it can be minimized by considering crisis management research and with the co-operation of public and private actors. By analyzing the impact on other sectors, we can reduce these negative impacts (Ritchie 2004). Kontogeorgopoulos (1999) states that it is important to cope with these negative situations, as memories after crises are short and soon overcome.

The studies published on the impact of COVID-19 in the tourism industry are mainly conceptual and rely on the idea that tourism activity should be reimagined in a more sustainable and resilient way. However, both researchers and practitioners still need to address the consequences of the pandemic and the political-economic drivers and consequences (Mostafanezhad 2020) and decide whether the tourism industry should be reshapedor not in the short, medium or long term. Although this pandemic has not been eradicated, some expected future trends have been described. Ioannides and Gyimóthy (2020) state that the COVID-19 crisis is leading to the decline of certain mainstream business formats and, simultaneously, the emergence of others. It is possible that tourist will change their booking patterns and will tend to book later than they did before COVID-19 due to mobility constraints and to the uncertainty of their future job and economic situation (Smeral 2010). Specifically, they are planning shorter holidays than before and, for example, in terms of transportation patterns, a decline in intention of using public transport and an increase in the use of private cars has been observed, as people want to travel again but only once the pandemic is controlled ( $\mathrm{Li}$ et al. 2020a, b). Bulchand-Gidumal and Melián-González (2020) conclude that some changes in consumer behavior are taking place as a result of this pandemic, e.g. $28 \%$ of consumers plan to buy their tickets closer to their departure date and another 5\% state that they will probably avoid flights altogether, which will affect to sales and profitability of the airlines.

Some studies conclude that the effect of COVID-19 has been, is and will be different depending on the characteristics of the company. Lin and Chen (2021) indicate that the impact of COVID-19 on hotel's performance is different depending on the hotel characteristics: international tourist hotels with high product varieties and five-star hotels suffered a greater loss in revenue than other types of hotels, while hotels located in scenic areas and international chain hotels were less affected. Guo et al. (2021) indicate that the recovery of hotels with shorter operating years, higher quality amenities and services, and better brand image, was faster during the pandemic. Moreover, the comparison between different types of cities suggests that hotels in tourism-oriented cities recovered faster than those in commerce-oriented ones. Another way of increasing and speeding up the recovery from the pandemic is to consider the role of OTA and the information that they provide from suppliers, which should be continuously updated (Guo et al. 2021).

Specifically, very few articles have been published about the impact of disasters and crises in the cruise industry. Ryschka et al. (2016) indicates that the speed of response using social media, brand familiarity, and cultural values of the respondent affect perceptions of the corporate reputation of a cruise line after a crisis, and so corroborate Pan et al. (2021). This indicates that having a clear crisis communication plan might be beneficial to recovery. From the supply side, the products of the cruise industry are itineraries, which are based on mobility. Due to border and port closures to non-essential transit in most countries (Gössling et al. 2020), mobility has been extremely limited which was inevitably led to the cessation of cruise activity. From the point of view of demand, it is important to consider increasing worries about safety on cruise ships and the constraint it 
may represent, so it is important to improve tourists' feelings of safety and security and raise awareness of cruising standards and protocols (Hung et al. 2020). Up to now, cruise passengers were very confident in the safety and security measures adopted by cruise companies (Bowen et al. 2014). With the pandemic, the importance of hygiene and cleanliness has increased hugely, especially in the cruise industry, both in port and on board, as it is one of the key factors looked at when deciding to book a cruise (Whyte 2018). Fisher et al. (2018) insist on the importance of handwashing and passenger's awareness of protection/safety measures. Healthy Gateways (2020), co-founded by the Health Programme of the European Union, published an extensive document to provide general guidance, measures and protocols in order for the cruise industry to give an appropriate response to the pandemic. Moreover, there is evidence of doubts about whether or not to go on a cruise in the future (around 52\% according to Li et al. 2020a, b). To recover from this crisis and specifically speaking about the cruise industry, it is necessary to consider vaccines, the relaxation of travel restrictions, the implementation of additional health measures for passengers before to access the vessels, and the presence of a loyal clientele (Renaud 2020). Espinet et al. (2021a) outline the changes and challenges of the cruise industry after COVID-19, indicating that the impact will be different on each region or country, and describing the necessity of applying different measures and protocols accordingly. It may be the time to change the paradigm from "growth for development" to "edgrowth for liveability", which in the cruise industry implies small ships and locally controlled fleets promoting the development of a niche cruise industry (Renaud 2020).

Finally, when considering pricing strategies, research into the impact on prices after a crisis is scarce but a summary can be seen in Wut et al. (2021). Zhang et al. (2020) affirm that "tourists have a strong negative emotional reaction towards disadvantaged tourism-related prices in response to a high (vs low) infectious disease threat". It appears that a discount strategy is commonly applied after a crisis, as consumers hope to profit from last-minute bargains and cheaper deals and, for example, it is possible that consumers become more price sensitive, which could lead to price wars in order to obtain liquidity, and to the delaying of investments and a deterioration in quality (Smeral 2010), although there is no clear evidence that this also happens in the cruise industry. In fact, Lai and Wong (2021) conclude that the reduction in prices is one of the strategies applied to survive from a pandemic. However, Kim et al. (2019) maintain that discounts may alleviate cumulative occupancy loss precipitated by a crisis but do not reduce cumulative RevPAR and delay both occupancy and RevPAR recovery times as competitors also reduce their room rates in times of crisis. Hu et al. (2021) conclude that the importance of price has decreased during the pandemic and the importance of quality and service has increased. These results are coherent with those obtained by Lin and Chen (2021) who suggest that price elasticity of demand after COVID-19 in the hotel industry is smaller than one, so the demand hardly responds to the variation of prices. However, Pan et al. (2021) conclude that $52 \%$ of the respondents of the study would take a cruise if there were large discounts and $26 \%$ that would consider it, suggesting that discounts could allow cruise companies to recover faster.

\section{Materials and methods}

This research has been developed using a database created at the rate of one per month by the authors from February 2019 to March 2021. Specifically, the authors collected the final prices paid by customers from a leading Spanish OTA. These prices were collected using web scraping techniques after which the authors extensively evaluated the quality of the data obtained and eliminated inconsistent and incomplete observations. The final database includes 1,644,098 prices. These prices correspond to itineraries of cruises around the world that depart within the period of one day after the date of capture to 730 days after ( 2 years) and whose length ranges from 2 to 14 nights, the most common lengths of cruise itineraries. The whole range of cruise prices is quite difficult to capture as there is not any official source including them so information collection requires extra effort.

As the pandemic was declared on the 11th March 2020 and the main aim of this research is to address the effect of COVID-19 on cruise package prices, the approach towards analysing the database was to compare prices 13 months before this date $(863,919$ observations) and 13 months after this declaration (780,179 observations), thereby obtaining reliable results month by month.

The database includes the following attributes: date of departure, cruise company, cruise ship, number of nights of the itinerary, type of cabin, CLIA zone of departure, the number of days between the date of capture and the date of departure, the antiquity of the ship, the tonnage of the ship, the ship rating and the final price paid by customersincluding port taxes.

After data collection, data analysis is twofold. First, descriptive analyses comparing price availability and average prices are done, in order to get general view of the situation. Second, a hedonic regression model is implemented in order to isolate the impact of attributes on prices before and after COVID-19. This methodology has been widely used in the analysis of the tourism industry (see, for instance, Espinet et al. 2003; Haroutunian et al. 2005), including the cruise industry (see, for instance, Espinet et al. 2021b; Espinet 2018; Niavis and Tsiotas 2018). It is a useful 
methodology to assess the isolated impact of each characteristic on the whole price of the tourism package. The hedonic pricing model is assumed to be semi-logarithmic (i.e. In price) and each of the attributes of the cruise package are assessed to better explain these changes in cruise packages before and after the declaration of the COVID-19 pandemic.

\section{Results}

The results of this research are divided into two parts. First, the comparison of price and itinerary availability pre and post the declaration of the COVID-19 pandemic is given. Second, the study of the evolution of cruise prices through descriptive and hedonic prices models is provided. Henceforth, pre-COVID-19 and post-COVID-19 refer to 13-month periods before and after COVID-19 was declared a pandemic in March 2020.

\section{Availability of itineraries}

First it is interesting to address the evolution of the itineraries available over the 26 months of the analysis, 13 months before COVID-19 was declared a pandemic (February 2019 to February 2020) and 13 months after (March 2020 to March 2021). Table 1 displays the number of itineraries available per month of data capture and the number of days between the date of data capture and the date of departure.

The number of itineraries available in the thirteen months prior to COVID-19 was 238,208 and in the thirteen months after COVID-19 was declared a pandemic, it was 217,060 , a reduction of 21,148 itineraries. This difference is distributed as follows (in percentage terms): $33.2 \%$ correspond to itineraries that depart from the date of capture to 30 days later, $28.7 \%$ from 31 to 60 days, $15.1 \%$ from 61 to 90 days and $6.2 \%$ from 91 to 120 days. The sum of the first 120 days represents $83.2 \%$ of the reduction. In percentage terms, there is a reduction of $8.9 \%$, which is distributed as follows: $83.6 \%$ up to 30 days; $58.9 \%$ from 31 to 60 days; $28.9 \%$ from 61 to 90 days and $10.9 \%$ from 91 to 120 days (Fig. 1). It is clear that the main reduction in the availability of itineraries is when the cruise departs within 120 days from the date of data capture, so in the very short term. This can be explained by the fact that there is a lot of uncertainty surrounding whether the cruise will be able to depart, until the last minute. Although the cruise was not expected to depart, prices were still displayed to maintain the activity of the website and the flow of information. The strategy of publishing prices in spite of the assumption that the service cannot be provided has been observed in tourism sectors such as hotels and theme parks.

The analysis by CLIA zone of departure discloses relevant differences in the itineraries available (Fig. 2). The areas where the offering is most reduced are Asia without China (-33.0\%), Mexico/Central America (-26.1\%) and Canada/New England (- 25.5\%). The three most important zones, i.e. the Caribbean, the Mediterranean and the North of Europe show completely different behaviour, with decreases in availability of $-14.4 \%,-0.6 \%$ and $-9.8 \%$, respectively, that could be due to the proximity of the Spanish market in spite of the cease of the activity.

\section{Price analyses}

The analysis of the variation in prices was carried out in two steps. First, a comparison of the average prices was made and second, a hedonic model was carried out to identity the variation in prices for cruises with the same itinerary and the number of days between the date of data capture and the date of departure.

\section{Average price}

On average, prices after the declaration of the COVID-19 pandemic increased by $0.9 \%$. This percentage is different depending on the attributes analysed. When considering the type of cabin, the differences in price range from $-1.9 \%$ for inside cabins to $+2.6 \%$ for ocean cabins. This may be because of the increase in demand for cabins with windows and therefore fresh air. The analysis by cruise companies ranges from $-17.8 \%$ for Crystal to $+21.8 \%$ for Silversea, revealing large differences price strategies. In fact, 16 cruise companies are below the average and 9 over the average for price changes. The analysis by CLIA zone of departure ranges from $-8.9 \%$ in China to $+27.1 \%$ in South America, revealing different price strategies between zones of departure. In fact, 6 of the zones are below the average and 7 are over the average. The analysis by number of days between the date of capture to the date of departure ranges from $-4.7 \%$ when the difference of days is $661-990$ to $+14.5 \%$ when the number of days is $0-30$. In fact, the highest increase in average prices are for departures in the shortterm. When comparing prices taking into account the size of the ship - tonnage - price differences range from $-5.7 \%$ for ships from 100,001 to 150,000 tonnes to $+19.4 \%$ for ships up to 50,000 tonnes, revealing huge differences depending on the size of the vessel. In parallel, when comparing prices according passenger capacity, price changes range from $-6.5 \%$ for ships with a capacity of 3001 to 4000 passengers to $+17.3 \%$ for ships which can carry up to 2000 passengers. The results of the analysis by tonnage and passengers show similar results, as can be expected, as the more tonnage a ship has the more passengers it can carry. Consequently, no clear and direct correlation between the size or capacity of the ships and prices is observed. 


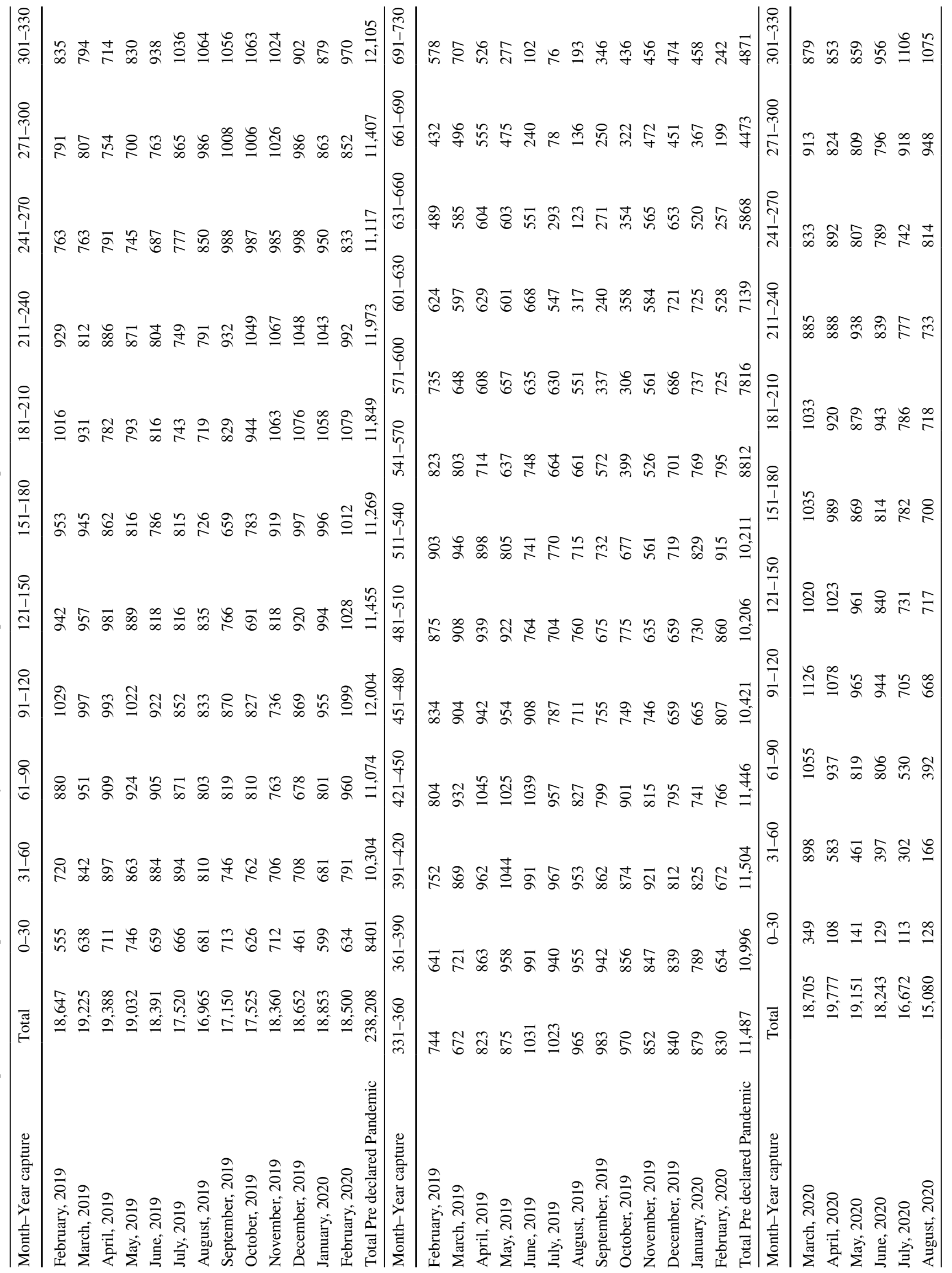

s. 


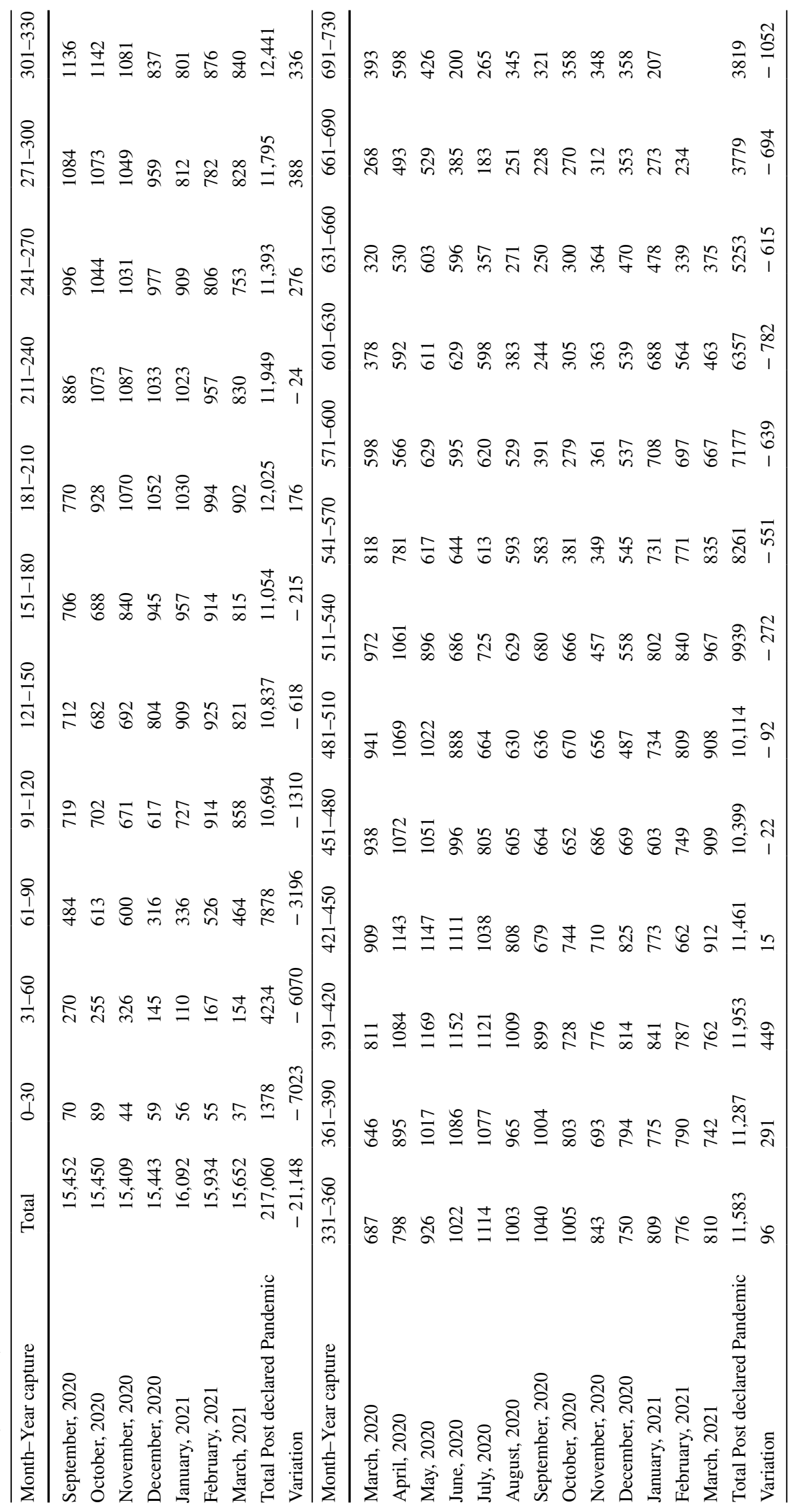




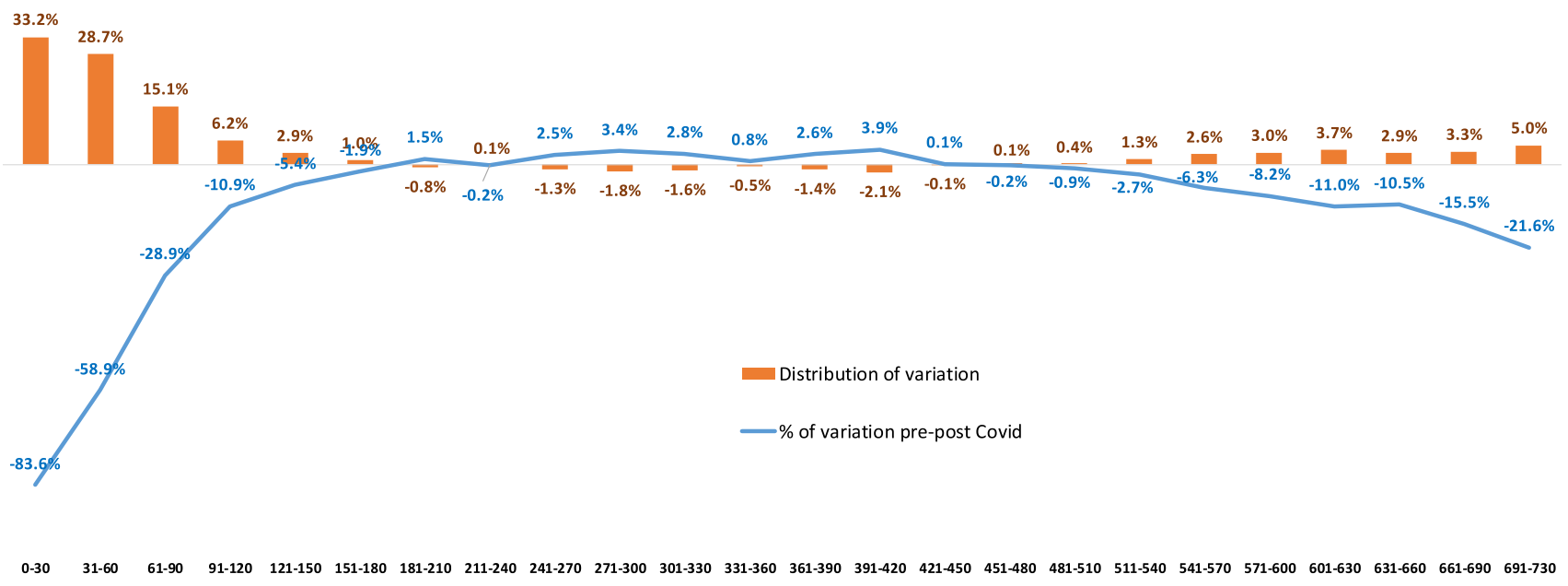

Fig. 1 Difference of itinerary availability before and after COVID-19 according to the days between data capture date and itinerary date of departure

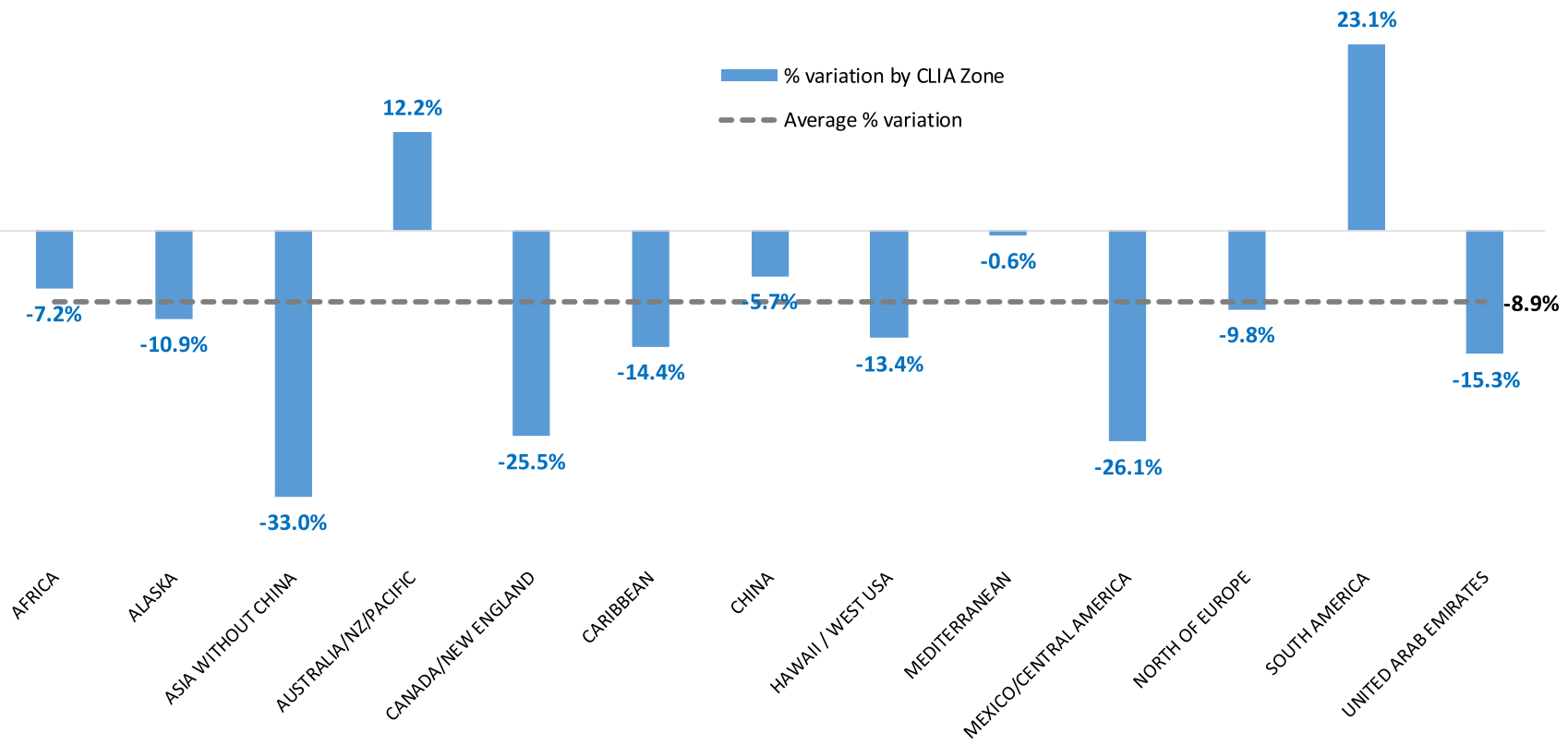

Fig. 2 Percentage of difference of available itineraries depending on the CLIA zone of departure. Percentage of variation in adjusted prices compared to February 2019

Analysis by antiquity reveals that prices vary from $-0.9 \%$ for the newest ships to $+19.7 \%$ for the ships whose antiquity is between 11 and 15 years. However, as happens with ship capacity and size, this correlation is not direct. Finally, the comparison by ship rating shows that the price change range is from $-2.7 \%$ when ships have 4 stars to $+2.9 \%$ when ships have 5 stars, indicating low correlation in this sense, too.

In summary, the fewest differences are found when comparing the type of cabin (the range is a $4.6 \%$ ), which indicates that cruise companies use a homogeneous strategy towards pricing within the same cruise ship. The highest differences are observed when comparing cruise companies (the range is 39.6\%) and CLIA zone of departure (the range is $36.0 \%$ ) revealing that cruise companies apply different strategies and they do so according to the zone of departure.

\section{Adjusted price}

Different specifications of the same regression model have been carried out and analysed to see the peculiarities according to the following 7 characteristics: type of cabin; cruise company; CLIA zone of departure; number of days between 
data capture date and date of departure; the antiquity of the ship; the ship tonnage; and the ship rating. The global model has an adjusted $R^{2}$ of 0.833 and, from the 88 specifications carried out according to each characteristic, 79 have obtained values over 0.70 , which can be considered robust and reliable results and models.

Although the average price can be a first indicator of the evolution of prices, in-depth analysis to obtain the differences pre-COVID-19 and post-COVID-19 consists of the comparison of the prices considering the same characteristics, in other words, the adjusted price, which has been estimated using the hedonic approach. The variation in prices when adjusting them by the same itinerary and the number of days between the date of capture and the date of departure is $-4.3 \%$ (Table 2 ), which shows some differences from the price variation of the average price $(+0.9 \%)$. The reason is that the analysis of the average price has a different composition that the analysis of adjusted prices.

When considering the type of cabin, the differences in price range from $-5.0 \%$ for balcony and suite cabins to $-3.7 \%$ for ocean cabins. The range of differences, $1.3 \%$, is small, which can be accounted for the fact that the price strategies are homogeneous in the same ship regardless of the type of cabin. The main reduction in the most expensive type of cabins-balcony and suites-could be the result of less willingness to pay more, in spite of the space and luxury they provide. The analysis by cruise companies ranges from $-16.5 \%$ for Crystal to $+12.4 \%$ for Costa Cruises - a difference of $29.0 \%$-revealing high differences between cruise price strategies. In fact, 9 cruise companies have increased their prices. The five biggest cruise companies according to Medcruise (2021) that represent $54.5 \%$ of the industry, have all decreased their prices: Royal Caribbean $(-4.3 \%)$, Carnival (-11.1\%), MSC (-10.0\%), Norwegian $(-8.9 \%)$ and Princess $(-8.9 \%)$. However, the following 4 cruise companies that represent $20.9 \%$ of the industry capacity have all increased their prices: Aida $(+0.3 \%)$, Costa Cruises $(+12.4 \%)$, Celebrity (+5.3\%) and Holland America (4.5\%). In spite of these results, from individual analysis it is not possible to conclude that the differences in prices depend on the capacity of the cruise ship, so no common factors can be defined.

The analysis by CLIA zone of departure ranges from - $10.6 \%$ in Mexico/Central America to $+2.1 \%$ in Canada/ New England-a difference of $12.7 \%$-revealing different price strategies according to the zone of departure, which could be due to the reopening strategy of ports and the quite diverse governmental measures and protocols applied. The analysis by number of days between the date of price capture to the date of itinerary departure ranges from $-8.1 \%$ when the difference of days is $0-30$ to $-0.7 \%$ when the number of days is $691-730$, a difference of $7.4 \%$. As happened above, from the results no common conclusions can be defined.
When comparing prices according to the size of the ship-tonnage-prices range from $-6.8 \%$ for ships from 100,001 to 150,000 to $-1.8 \%$ for ships up to 50,000 . In parallel, in the comparison depending on passenger capacity, prices range from $-7.4 \%$ for ships from 3001 to 4000 passengers to $-2.8 \%$ for ships up to 2000 passengers. These results are similar because the more tonnage a ship has the more passengers it can carry. In sum, bigger ships have higher reductions as they need to fill their ships in order to obtain enough revenue and profits, which can come from on board services (29\% of revenue according to Medcruise 2021).

The analysis by ship antiquity reveals that prices vary from $-5.3 \%$ of the ships from 6 to 10 years old and $-4.7 \%$ up to five years old to $+3.1 \%$ of the ships whose antiquity is between 11 and 15 years. It is observed that the newest ships have reduced prices and the oldest have increased prices. This could be due to the fact that the oldest ships have been amortized so that they have obtained enough benefits and this puts less pressure on prices. Moreover, the newest ships are the bigger ones, so the results are commercially coherent.

Finally, the comparison by ship rating shows that the range is from $-5.8 \%$ when ships have 4 stars to $-2.5 \%$ when ships have 5 stars. It could be predicted that the more luxurious the ship is, the less the price has an impact, as they achieve differentiation through other methods. However, there is no clear trend in the data that shows it has happened in the cruise industry during the pandemic.

In summary, the fewest differences take place when comparing the type of cabin (the range is $1.3 \%$ ), which indicates that ships use a homogeneous strategy. The major differences in prices come from the individual strategy of the cruise companies, which depends on the zone of departure, which could be an indicator of the impact of COVID-19 at each location and the measures taken in these locations which affect the cruise industry. In fact, the impact of COVID19 is expected to be different depending on the individual cruise company and apparently the luxury segment and the river cruises will see less impact (Espinet et al. 2021a). As a result, although cruise supply remains stable, sales and incomes can vary the market share. Another interesting observation is that, although the differences in prices using the average price and the adjusted price are relevant, they conceptually reveal the same types of strategy.

After considering price comparisons according to different attributes, it is also interesting to address the monthly evolution of the adjusted prices (Fig. 3). Since the pandemic was declared and all ships had to cease their activity, prices began to decrease, and the biggest reductions took place between July and September 2020. Moreover, the difference in prices comparing the same month pre and post COVID19 has increased over the most recent months analysed: December 2019/2020 - 7.8\%, January 2020/2021 - 6.3\% 


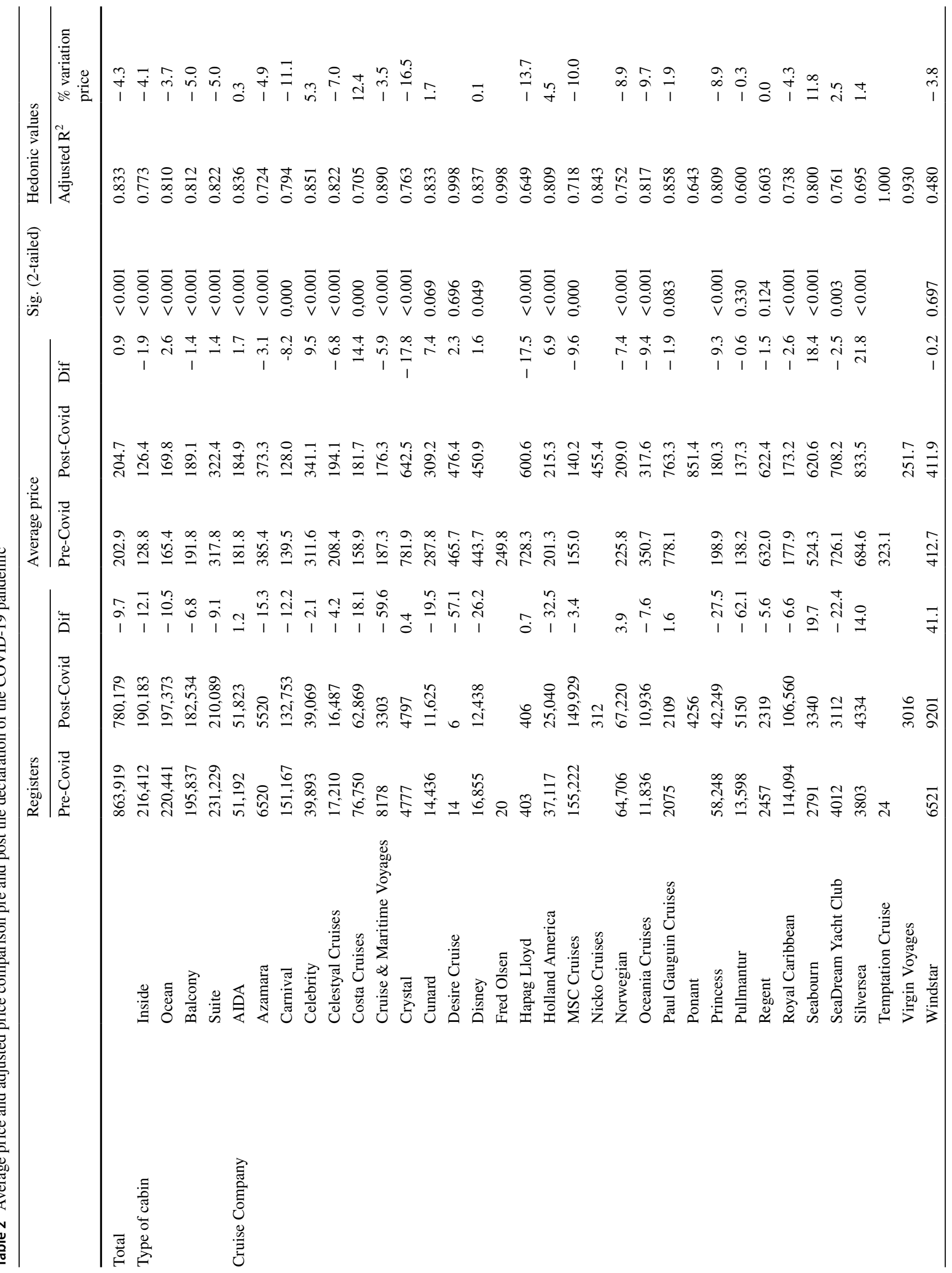

桨 


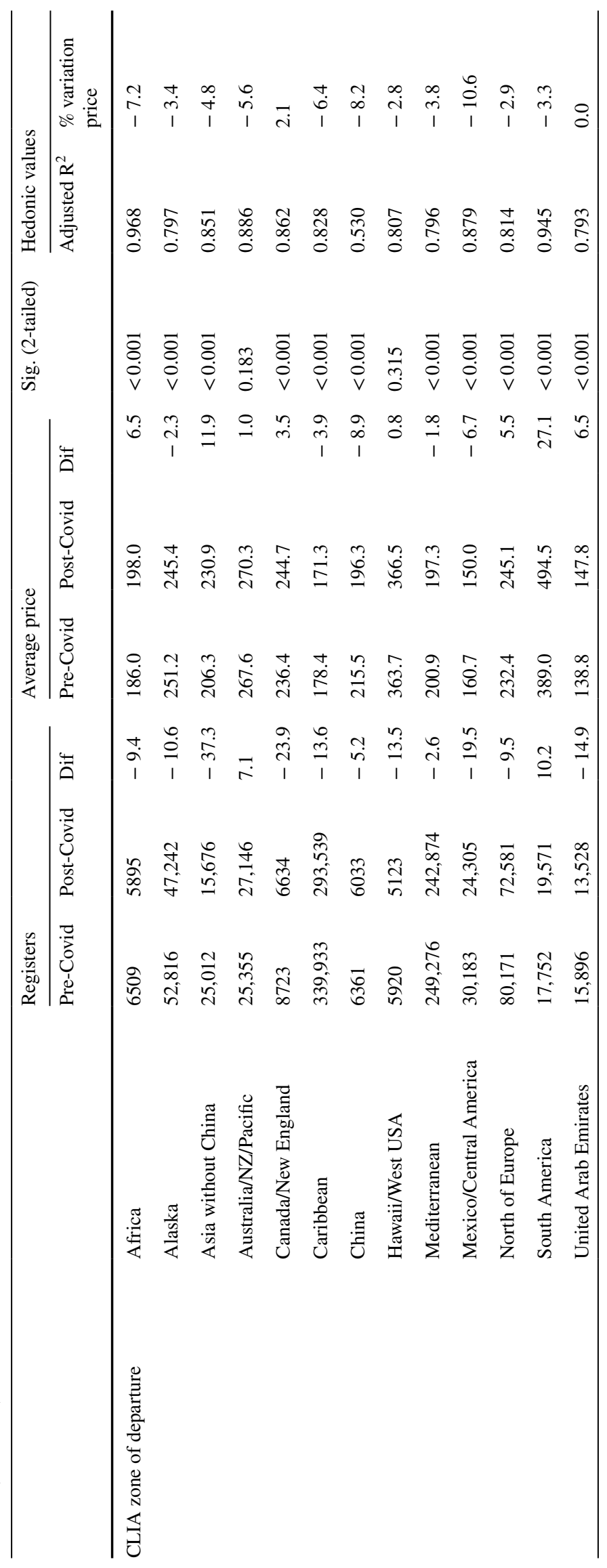




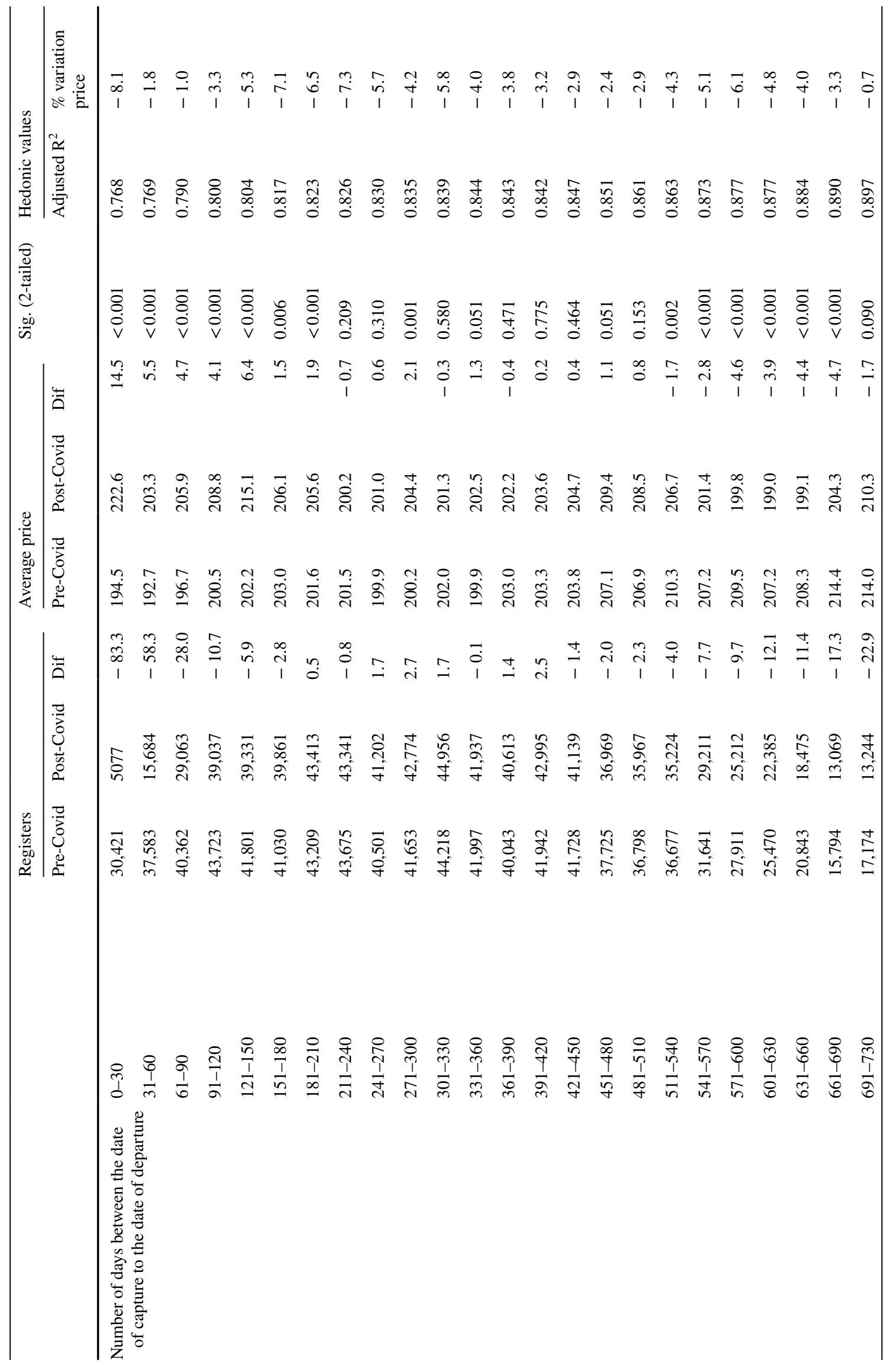

桨 


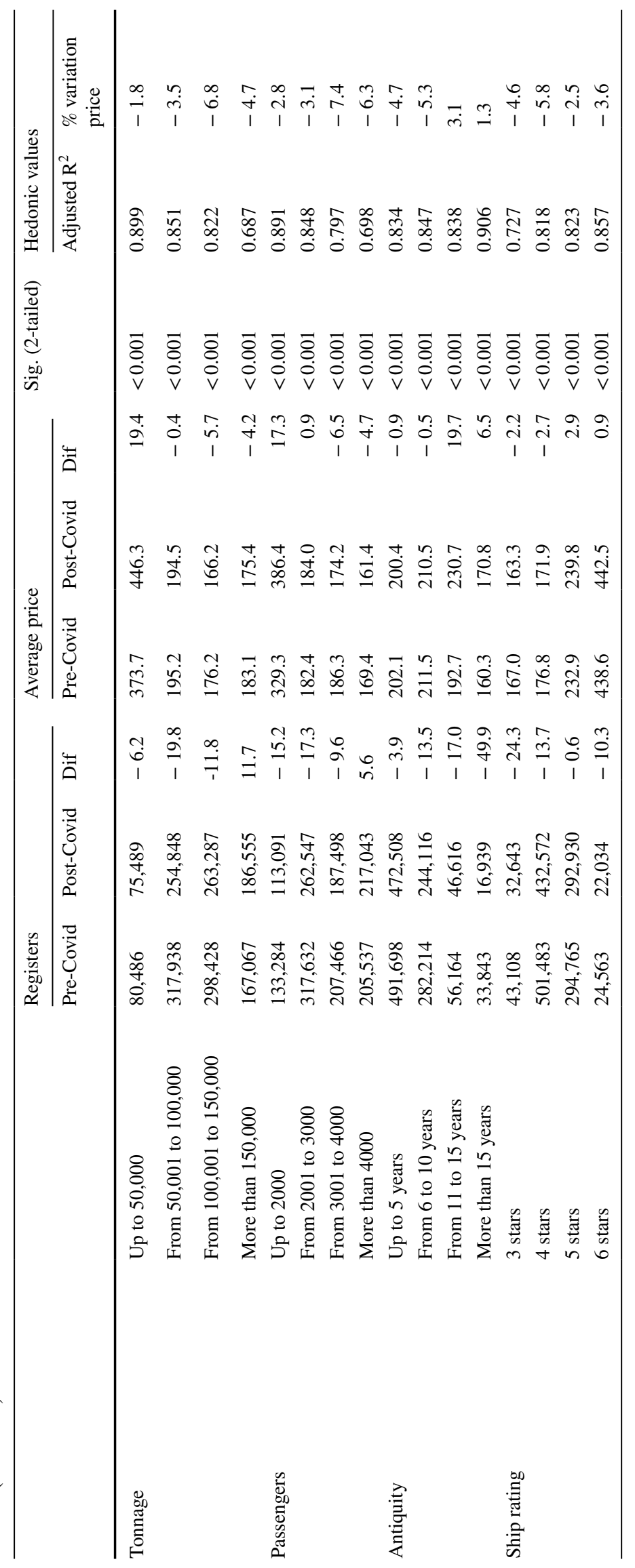




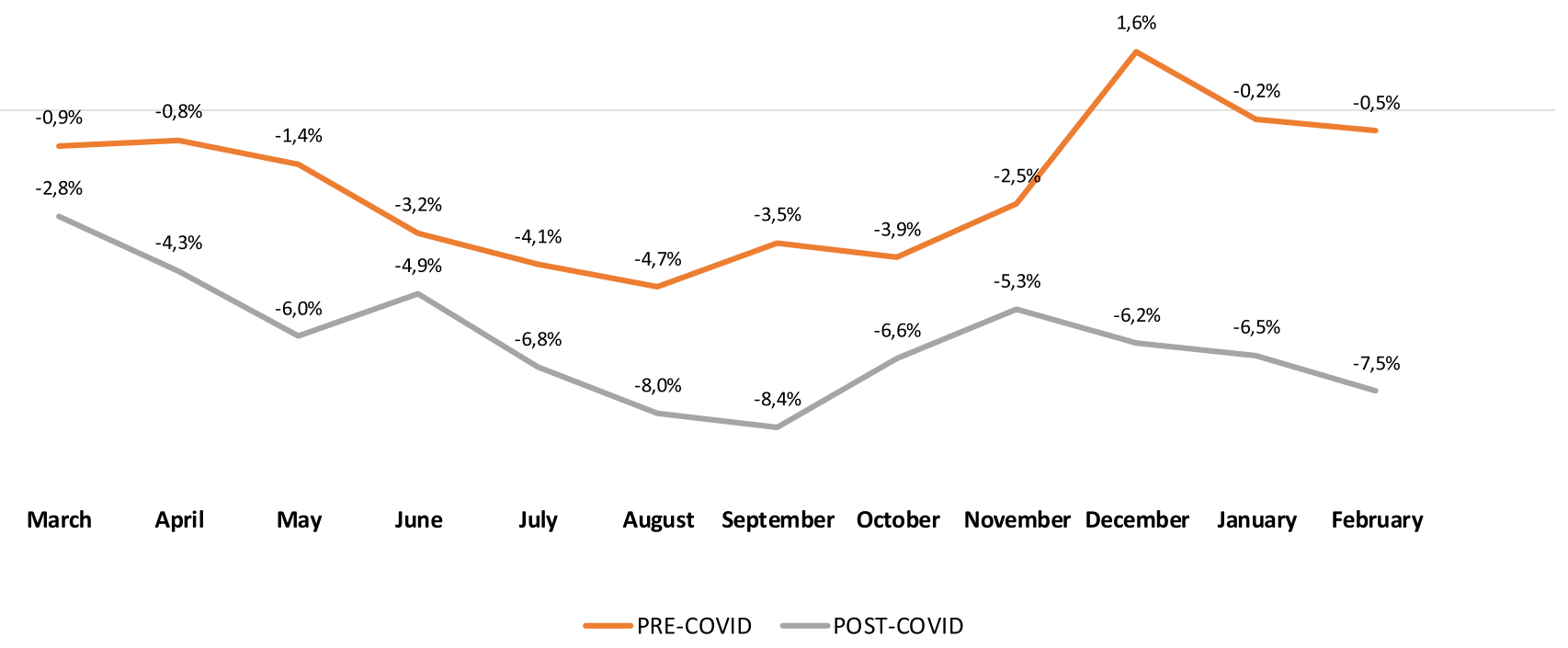

Fig. 3 Percentage of variation in adjusted prices compared to February 2019

and February 2020/2021 - 6.9\%. This could be due to the fact that cruise companies are thinking about resuming their activity and, in order to attract customers, one of the common strategies is to reduce prices as indicated in literature review (i.e. Lai and Wong 2020).

\section{Conclusions}

The aim of this study is to estimate how prices have changed in the cruise industry since COVID-19 was declared a pandemic. This is an empirical study supported by an extensive database created by the authors from a leading Spanish OTA (1,644,098 prices) and can be considered a pioneering study into the variation of prices in the tourism sector, in this case specifically in the cruise industry, since COVID-19 was detected. The use of the information from an OTA has the advantage that prices of different cruise companies are homogeneous as they are provided from the same source and that OTA are a common source from which to obtain information, attract customers and book (De Pelsmacker et al. 2018) as they are able to improve the sales in this case of the cruise companies (Guo et al. 2021). From a methodological perspective this study uses the hedonic approach, very common in the tourism industry in this type of analysis.

The main results indicate that the itineraries available were reduced by $8.9 \%$ and prices were reduced, on average, by $4.3 \%$ although there are relevant differences between cruise companies, zone of departure, size, antiquity and rating of the ships, and the number of days between the date of data capture and the date of cruise departure. Due to the uncertainty of the situation, decision-making in the time of crisis is very complex.
From a managerial point of view, it is obvious that cruise companies will have higher costs derived from the new requirements of COVID-19 and, when they resume their activity and for some time, they will not be able to use their full capacity. This will affect the level of revenue and profit of the cruise companies. In this sense, several strategies are available. Regarding revenue, a very common strategy is to reduce price, as it is relatively easy to adjust them (Arbulú et al. 2021) as has been observed in this research and considering that consumer behaviour has changed with consumers booking closer to the departure date (Bulchand-Gidumal and Melián-González 2020). These results support the findings that consumers are willing to go (52\%) or would consider going (26\%) on a cruise if there are large discounts (Pan et al.2021). However, some previous experience in hotels indicates that the strategy of applying discounts during a recession does not work (Kim et al. 2019) and discounted prices for cruise trips are likely to make this sector's economic recovery much more difficult (Gössling et al. 2020). In fact, in spite of a tendency towards an oligopolistic market in the hotel industry, prices are set by adding a small profit margin to the costs of the package holiday, making it hard to use general price reductions as a way of boosting demand (Alegre and Sard 2015). It is also important that cruise passengers do not get used to lowered cabin rates as it would be difficult to sell the cabins again at higher prices when the demand is recovered, affecting profits in both the mid and long term (Kim et al. 2019). Another way to attract customers is to provide extra security measures and to offer a clear differentiated service (Espinet et al. 2021a; Guo et al. 2021), which include new specific services on the ship as onboard revenues represent 29\% of the total (Medcruise 2021). From the point of view of costs, cruise companies 
can adjust them by identifying those more relevant and to try to optimize them so that they can improve their profits. For example, they could negotiate their commissions with agents-this represents $15 \%$ of the costs (Medcruise 2021) -, through changing their percentage or setting another structure of commissions, in order to benefit both. Another possible strategy could be to reduce their operating costs and payrolls, which represent $29.9 \%$ and $12.6 \%$, respectively (Medcruise 2021), although these measures should avoid to have a negative impact on image and reputation, which at the end affect the positioning of the cruise companies (AlonsoAlmeida et al. 2015). In all cases, the image of cruise companies (Ryschka et al. 2016), the way they communicate after a crisis (Liu et al. 2016) and media will play a key role (Guo et al. 2021) in the recovery of the industry.

The main limitation is that it is still too early to analyse the real impact of COVID-19 on prices and the consequent managerial decisions. For this reason, further research is needed in order to know not only the specific impact on prices but also what are the best strategies to benefit cruise companies and passengers after a period of this kind of crisis and if these strategies will maintain in the future or will be temporary.

\section{References}

Alegre, J., and M. Sard. 2015. When demand drops and prices rise. Tourist packages in the Balearic Islands during the economic crisis. Tourism Management 46: 375-385.

Alonso-Almeida, M.D.M., K. Bremser, and J. Llach. 2015. Proactive and reactive strategies deployed by restaurants in times of crisis: Effects on capabilities, organization and competitive advantage. International Journal of Contemporary Hospitality Management 27 (7): 1641-1661.

Arbulú, I., M. Razumova, J. Rey-Maquieira, and F. Sastre. 2021. Can domestic tourism relieve the COVID-19 tourist industry crisis? The case of Spain. Journal of Destination Marketing \& Management 20: 100568.

Bowen, C., P. Fidgeon, and S.J. Page. 2014. Maritime tourism and terrorism: Customer perceptions of the potential terrorist threat to cruise shipping. Current Issues in Tourism 17 (7): 610-639. https://doi.org/10.1080/13683500.2012.743973.

Bulchand-Gidumal, J., and S. Melián-González. 2020. Post-COVID-19 behavior change in purchase of air tickets. Annals of Tourism Research 87: 103129.

Choquet, A., and A. Sam-Lefebvre. 2021. Ports closed to cruise ships in the context of COVID-19: What choices are there for coastal states? Annals of Tourism Research 86: 103066.

CLIA. 2020. FAQs: The Cruise Community and COVID-19. Retrieved from https://cruising.org/-/media/Facts-and-Resources/CruiseIndustry-COVID-19-FAQs_June-2020

De Pelsmacker, P., S. Van Tilburg, and C. Holthof. 2018. Digital marketing strategies, online reviews and hotel performance. International Journal of Hospitality Management 72: 47-55. https://doi. org/10.1016/j.ijhm.2018.01.003.

Espinet, JM ${ }^{\mathrm{a}}$. 2003. Effect on prices of the attributes of holiday hotels: A hedonic prices approach. Tourism Economics 9 (2): 165-177.
Espinet, J.M. 2018. Global and local pricing strategies in the cruise industry. Journal of Revenue and Pricing Management 17 (5): 329-340.

Espinet, JM"., A. Gassiot-Melian, and R. Rigall. 2021. COVID-19 in the cruise industry: changes and challenges. Journal of Sustainable Tourism 29 (1): 1-20. https://doi.org/10.13140/RG.2. 2.27343 .41129$.

Espinet-Rius, J.M., A. Gassiot-Melian, and R. Rigall-I-Torrent. 2021. Price determinants and classification of tactical pricing decisions in the cruise industry. Maritime Policy \& Management 48 (2): 239-258. https://doi.org/10.1080/03088839.2020.1843723.

Faulkner, B. 2001. Towards a framework for tourism disaster management. Tourism Management 22 (2): 135-147.

Fisher, J.J., B.A. Almanza, C. Behnke, D.C. Nelson, and J. Neal. 2018. Norovirus on cruise ships: Motivation for handwashing? International Journal of Hospitality Management 75: 10-17.

Gössling, S., D. Scott, and C.M. Hall. 2020. Pandemics, tourism and global change: A rapid assessment of COVID-19. Journal of Sustainable Tourism 29 (1): 1-20. https://doi.org/10.1080/ 09669582.2020.1758708.

Guo, L., K. Liu, Y. Song, and Z. Yang. 2021. Recovering hotel room sales during the COVID-19 pandemic: lessons from OTA information using the quantile regression approach. Current Issues in Tourism 20: 1-21.

Haroutunian, S., P. Mitsis, and P. Pashardes. 2005. Using brochure information for the hedonic analysis of holiday packages. Tourism Economics 11 (1): 69-84.

Healthy Gateways. 2020. Interim guidance for preparedness and response to cases of COVID-19 at points of entry in the european union (eu)/eea member states (ms). Interim advice for restarting cruise ship operations after lifting restrictive measures in response to the COVID-19 pandemic. Version 1, 30.6.2020

Hu, F., T. Teichert, S. Deng, Y. Liu, and G. Zhou. 2021. Dealing with pandemics: An investigation of the effects of COVID-19 on customers' evaluations of hospitality services. Tourism Management 85: 104320 .

Hung, K., J.S. Lee, S. Wang, and J.F. Petrick. 2020. Constraints to cruising across cultures and time. International Journal of Hospitality Management 89: 102576. https://doi.org/10.1016/j.ijhm. 2020.102576.

Ioannides, D., and S. Gyimóthy. 2020. The COVID-19 crisis as an opportunity for escaping the unsustainable global tourism path. Tourism Geographies 22 (3): 624-632. https://doi.org/10.1080/ 14616688.2020.1763445.

Kim, M., W. Roehl, and S.K. Lee. 2019. Effect of hotels' price discounts on performance recovery after a crisis. International Journal of Hospitality Management 83: 74-82. https://doi.org/ 10.1016/j.ijhm.2019.04.006.

Kontogeorgopoulos, N. 1999. Sustainable tourism or sustainable development? Financial crisis, ecotourism, and the "Amazing Thailand" campaign. Current Issues in Tourism 2 (4): 316-332.

Lai, I.K.W., and J.W.C. Wong. 2020. Comparing crisis management practices in the hotel industry between initial and pandemic stages of COVID-19. International Journal of Contemporary Hospitality Management 32 (10): 3135-3156.

Li, J., T.H.H. Nguyen, and J.A. Coca-Stefaniak. 2020a. Coronavirus impacts on post-pandemic planned travel behaviours. Annals of Tourism Research. https://doi.org/10.1016/j.annals.2020.102964.

Li, Z., S. Zhang, X. Liu, M. Kozak, and J. Wen. 2020b. Seeing the invisible hand: Underlying effects of COVID-19 on tourists' behavioral patterns. Journal of Destination Marketing \& Management 18: 100502.

Lin, Y.C., and C.M. Chen. 2021. How do hotel characteristics moderate the impact of COVID-19 on hotel performance? Evidence from Taiwan. Current Issues in Tourism 20: 1-6. 
Liu, B., L. Pennington-Gray, and J. Krieger. 2016. Tourism crisis management: Can the extended Parallel Process Model be used to understand crisis responses in the cruise industry? Tourism Management 55: 310-321. https://doi.org/10.1016/j.tourman. 2016.02.021.

Medcruise. 2021. MedCruise data: Cruise Operations restart \& Cruise ships lay-up. Data collected since March 2020. Retrieved from https://www.medcruise.com/medcruisedata. Accessed 17 May 2021

Mostafanezhad, M. 2020. Covid-19 is an unnatural disaster: Hope in revelatory moments of crisis. Tourism Geographies 22 (3): 639645. https://doi.org/10.1080/14616688.2020.1763446.

Niavis, S., and D. Tsiotas. 2018. Decomposing the price of the cruise product into tourism and transport attributes: Evidence from the Mediterranean market. Tourism Management 67: 98-110.

Pan, T., F. Shu, M. Kitterlin-Lynch, and E. Beckman. 2021. Perceptions of cruise travel during the COVID-19 pandemic: Market recovery strategies for cruise businesses in North America. Tourism Management 85: 104275.

Renaud, L. 2020. Reconsidering global mobility-distancing from mass cruise tourism in the aftermath of COVID-19. Tourism Geographies 22 (3): 679-689. https://doi.org/10.1080/14616688.2020. 1762116

Ritchie, B.W. 2004. Chaos, crises and disasters: A strategic approach to crisis management in the tourism industry. Tourism Management 25: 669-683.

Ryschka, A.M., D.J. Domke-Damonte, J.K. Keels, and R. Nagel. 2016. The effect of social media on reputation during a crisis event in the cruise line industry. International Journal of Hospitality \& Tourism Administration 17 (2): 198-221.

Smeral, E. 2010. Impacts of the world recession and economic crisis on tourism: Forecasts and potential risks. Journal of Travel Research 49 (1): 31-38. https://doi.org/10.1177/0047287509353192.
Whyte, L.J. 2018. Eliciting cruise destination attributes using repertory grid analysis. Journal of Destination Marketing and Management 10: 172-180. https://doi.org/10.1016/j.jdmm.2018.11.003.

Wut, T.M., J.B. Xu, and S.M. Wong. 2021. Crisis management research (1985-2020) in the hospitality and tourism industry: A review and research agenda. Tourism Management 85: 104307.

Yang, Y., H. Zhang, and X. Chen. 2020. Coronavirus pandemic and tourism: Dynamic stochastic general equilibrium modeling of infectious disease outbreak. Annals of Tourism Research 83: 102913. https://doi.org/10.1016/j.annals.2020.102913.

Zhang, K., Y. Hou, and G. Li. 2020. Threat of infectious disease during an outbreak: Influence on tourists' emotional responses to disadvantaged price inequality. Annals of Tourism Research 84: 102993.

Publisher's Note Springer Nature remains neutral with regard to jurisdictional claims in published maps and institutional affiliations.

Josep Maria Espinet Rius is an assistant professor at the Universitat de Girona and Mediterrani in Spain in the faculties of Tourism and Economics. The main activity is carried out in the department of Business Control at CaixaBank. He holds a doctorate in economics from the Universitat de Girona. He specializes in price analysis, tourism studies mainly in the hotel and the cruise industry - and Big Data, areas where he has published articles in national and international publications.

Ariadna Gassiot-Melian is an assistant professor at the Universitat de Girona and Mediterrani in Spain in the faculty of Tourism. She holds a doctorate in Tourism from the Universitat de Girona. She specializes in tourism. 